\title{
Depth, Value, and Context
}

\author{
JUMBLY GRINDROD \\ University of Reading
}

\begin{abstract}
In this paper, I will consider the repercussions that epistemic contextualism has on capturing the distinctive value of knowledge. I will argue that the way that contextualist views capture the value of knowledge depends on the depth of the contextualism involved. To do so, I distinguish between superficial and deep contextualism, and I show how the latter is forced to contextualist epistemic value in a way the former is not. However, I then argue that if the superficial contextualist view does not contextualise epistemic value, it would nevertheless fail to properly capture the value of knowledge. If epistemic contextualism is true, then epistemic value should be contextualised.
\end{abstract}

Keywords: Epistemic value; epistemic contextualism; deep contextualism

\section{The Value of Knowledge}

The idea that there is a distinctive value associated with knowledge is famously discussed in Plato's Meno. We can reconstruct Socrates's reasoning in the following way. Knowing that $\mathrm{p}$ and merely truly believing that $\mathrm{p}$ have the same practical value in terms of being action-guiding. If I desire to get to Larissa, then whether I know that the Ai road will get me there or I truly believe that the AI road will get me there, the result of my practical reasoning and subsequent action will be the same. In this respect, true belief and knowledge seem on a par. Despite this similarity between knowledge and true belief, we want to preserve the following principle:

KVB: Knowledge is more valuable than merely true belief.

The plausibility of this principle can easily be brought out by considering the following thought experiment schema. Suppose I believe truly that $\mathrm{p}$ in a way

Contact: Jumbly Grindrod <j.grindrod@reading.ac.uk> 
that falls short of knowledge. An omnipotent being asks me if I would like to have my true belief replaced with knowledge. The natural answer here is the affirmative one, regardless of what the content of $\mathrm{p}$ is. Consider the opposite situation, where I know that p, but an omnipotent being asks me whether I would replace my knowledge that $\mathrm{p}$ with a merely true belief. The natural answer is the negative one, regardless of what the content of $\mathrm{p}$ actually is. Our preferences are indicative of the truth of KVB.

If $\mathrm{KVB}$ is true, we require some account of how whatever it is that distinguishes knowledge from mere true belief provides a kind of further value that is distinctive of knowledge. Some seek to provide an explanation of why KVB is true by appealing to something like the following:

VK: There is a distinctive value associated with knowledge.

However, we should be careful here, as VK is a principle that could be read in at least two ways. To see this, consider an obviously false theory of knowledge as pleasurable, true belief. $S$ knows $\mathrm{p}$ iff $\mathrm{S}$ believes $\mathrm{p}, \mathrm{p}$ is true, and $\mathrm{S}$ gains pleasure from her belief. With this view in hand, we could easily do justice to KVB by accounting for the superior value of knowledge over true belief by pointing to the value of pleasure. In that sense at least, we could account for the truth of VK. But on a stronger reading of $\mathrm{VK}$, the pleasurable true belief theory would fail to meet it. On the pleasurable true belief account, the further value possessed by knowledge over true belief is solely due to the fact that knowledge is pleasurable, and that pleasure is itself valuable. But this doesn't capture the idea that there is some valuable property that is distinctive of knowledge as knowledge, because the property of causing pleasure is a fairly common property that many things other than knowledge possess. ${ }^{1}$

And yet many think we do have good reason for defending VK, even on its stronger reading. One such reason could be viewed as metaphilosophical: namely, that this explains why philosophers throughout history have considered knowledge to be of such philosophical importance. Why, for example, have philosophers been so worried that certain sceptical arguments purport to show that we know close to nothing? After all, there are a number of ways we can describe our epistemic position without appeal to knowledge, by using belief talk, epistemic modals, reason-talk, evidence-talk, forms of assertion, probability, etc. If it turns out that we don't have knowledge, we would still have epistemic lives to live.

1. VK should not be read as the claim that knowledge has intrinsic value. The issue of intrinsic versus extrinsic value is orthogonal to the distinction drawn here. For example, VK might be accounted for by claiming that knowledge provides a unique kind of relation to the truth, but that its value is nevertheless derived from the value of truth. Knowledge, then would have an extrinsic form of value, but VK would nevertheless be captured. 
A natural answer to this question is that knowledge holds a kind of privileged position over other epistemic states. It has a kind of importance, and is indicative, as BonJour (2010) puts it, of "full cognitive success". This is why we consider knowledge to be of such importance in our epistemic lives and this is why knowledge (as opposed to, e.g., pleasurable true belief) is of such philosophical importance. This kind of response leads us to something very close to VK. We can find numerous instances of this appeal to a metaphilosophical consideration in the epistemic value literature. For instance, DePaul states:

If, on the other hand, knowledge lacks value, then efforts to analyse knowledge may not have been doomed from the start, but they seem pointless: why would anyone care what knowledge is if it has no special value? And all the energy invested into arguments for and against skepticism would seem to be wasted as well: why should we get ourselves in such a knot about whether it is possible to have something that has no distinctive value? (2009: 113)

The thought is that there is something distinctively valuable about knowledge that explains why it is of such philosophical importance and why it is of such importance in our everyday lives. Now I don't take this metaphilosophical reason to be the final word on the matter regarding the truth of VK, but I certainly think it speaks in favour of it. This paper is primarily concerned with capturing the more modest claim of $\mathrm{KVB}$, but we will return to consider VK in Section 5 .

A great deal of contemporary work has focused on the value of knowledge. In particular, a further problem has been recognised by the likes of Zagzebski (2004) and Kvanvig (2004), among others, known as the swamping problem. This is that it is not sufficient to identify some valuable property that knowledge has and true belief lacks, because the value of this property may itself be parasitic upon a property that true belief does have (i.e., that it is true, or that it is a belief). Such a property would add no further value to true belief. So identifying such a property would not explain the fact that knowledge is more valuable than mere true belief. This is an interesting further problem regarding the value of knowledge, but it is not the focus of this paper. Instead, this paper is concerned with the prior issue outlined by Socrates of capturing the weaker idea that knowledge is more valuable than mere true belief (i.e., KVB) and the related idea that there is a distinctive value associated with knowledge (i.e., VK).

Still, it might be thought that I cannot dismiss the swamping problem so easily. For example, Kvanvig (2004) has argued that the project of finding an account of knowledge that captures all cases of knowledge (in particular, that captures the intuitive results of Gettier cases) and that makes good of the idea that 
knowledge is more valuable than any proper subset of its parts is an impossible task. So perhaps this should lead us to be sceptical as to whether we can provide an account of knowledge that will make good of KVB. But in fact, Kvanvig can allow that knowledge is more valuable than mere true belief. What he will not allow is that there is some valuable property present in knowledge and lacking in true belief and that this property serves to distinguish between Gettiered true beliefs and knowledge. To use Pritchard's (2010) terminology, Kvanvig allows that there may be some solution to the primary value problem of how knowledge is more valuable than mere true belief, but doesn't allow that there is a solution to the secondary value problem of how knowledge is more valuable than any proper subset of its parts. My focus in this paper is on the primary value problem. The cases I will consider are not cases where we compare knowledge to some Gettiered belief, but where we compare knowledge to true beliefs that fall short of knowledge in some more traditional sense. In that respect, even Kvanvig could agree that in every case I am concerned with, knowledge is more valuable than mere true belief.

The issues covered thus far will be familiar to those well-acquainted with the contemporary discussion on the value of knowledge. The interest of this paper is how claims such as KVB and VK could be captured given the currently popular view that what we mean when we talk about "know" can vary across different contexts of utterance. This idea is most closely associated with epistemic contextualism, and it is to this view that I now turn.

\section{Epistemic Contextualism}

Epistemic contextualism is the view that sentences of the form "S knows p" can vary in truth value across different contexts of utterance. The view is standardly defended via appeal to context-shifting experiments such as DeRose's (1992) bank case and Cohen's (1988) airport case. Contextualism seems to cast a particular light on the question considered in the previous section of why philosophers have traditionally been so concerned with knowledge. After all, if contextualism is true and the truth-conditional content of "know" differs across contexts, that is, "know" refers to different relations across different contexts, then which of those relations is of distinctive value and of philosophical importance?

One answer would be that while the meaning of "know" may shift across contexts, epistemologists only use the expression within a philosophical context, and so the fact that the expression holds different meanings in other contexts is not strictly relevant to the epistemological endeavour of investigating what philosophers mean by the term. Sosa (2000) argues for something like this position. It is what "know" refers to in a philosophical context that holds such epistemic 
value and is rightly the subject of epistemological study. This would be to accept contextualism but to claim that because philosophers confine themselves to a single context, knowledge talk remains invariant for philosophical purposes. This, however, is simply not plausible given the kinds of considerations that are typically raised in epistemological theorising. Epistemologists don't confine themselves to considering knowledge-related activities in the epistemologist's context. ${ }^{2}$ They draw upon many different aspects of life (particularly with the employment of thought experiments) in order to construct a theory of knowledge that encompasses our knowledge practices across all contexts. It seems that if contextualism about knowledge attributions is true, this can't be put to one side by the epistemologist. Instead, whatever epistemological claims are made about knowledge, they must be compatible with the context-sensitivity of knowledge attributions. Returning to the question of the value of knowledge, if we are to make good of the idea that knowledge possesses a distinctive kind of value such that it is more valuable than mere true belief, this too should be something that holds across the full range of possible contexts.

In this paper, I am interested in the ways in which epistemic contextualism can approach the idea that knowledge is more valuable than true belief, that is, how epistemic contextualism can account for KVB. I will argue that the manner in which contextualist proposals can capture the value of knowledge is dependent upon the depth of the contextualism. In the next section, I will introduce the distinction between deep and superficial contextualism.

\section{Deep versus Superficial Contextualism}

The distinction between superficial and deep contextualism can be applied to any contextualist view that states that a given set of sentences can vary in their truth conditional content across different contexts of utterance. The distinction is due to Stalnaker, who introduces it by first considering two alternative views on the nature of quantification, and then on the nature of indexicals:

Both sides will agree that we may speak the literal truth when we say such things as that there is no beer left, that all the children are accounted for, that everyone has gone home. So both sides in this debate are contextualists about the quantifiers, but according to one, but not the other, the context-dependence is eliminable, and so the contextualism is not just a

2. It seems doubtful that there would even be a single epistemology context. Epistemologists often proceed from many different starting points, often holding different assumptions as fixed. Assuming that contexts are at least partly defined by the assumptions held within a context, this means that different epistemologists will operate within different kinds of context. 
fact about the way our language is used to generalise, but a fact about the nature of generality. For the absolutist, the contextualism about quantifiers is superficial: though we in fact often let implicit contextual factors restrict our domain, we need not do so. There is an absolute domain (if I may speak loosely, with a singular term to refer to what is properly spoken of only in the plural) of which all other domains are restrictions, and we could in principle make all of our contextual restrictions explicit.

The kind of context-dependence that Kaplan's original theory of indexicals and demonstratives was aiming to model is also superficial in this sense. The context-dependence was in the relation between expressions of the indexical language and the propositions that they expressed, but the propositions themselves ("content" or "what is said", as opposed to "character") were characterised independently of context. Later, when the phenomenon of essentially indexical attitudes was recognised, Kaplan's theory was applied to a deeper kind of context-dependence.

(2008: 103-104)

Stalnaker's concern here is whether the context-sensitivity associated with an expression is a contingent truth about the expression, or whether the contextsensitivity had to have been in place in order to properly describe the phenomenon in question. In the case of non-absolutist views of quantification, the thought is that the restriction of the domain quantified over by expressions like "all" and "every" is a necessary process. ${ }^{3}$ But for those who think that unrestricted quantification is perfectly fine, the restriction that in fact occurs with such expressions is a superficial fact about those expressions. Something similar holds in the case of essentially indexical attitudes. The thought is that when I have a belief of the form "He is making a mess", some part of the belief or proposition believed is essentially perspectival or indexical, and so the context-sensitivity of the expression "he" - as an expression used to communicate this belief - is ineliminable. This would then be a form of deep contextualism. But if the apparently indexical nature of such beliefs can be outlined in some other way, perhaps by using nonindexical language, then the context-sensitivity associated with indexicals is not something required in order to properly convey the nature of such beliefs, and so the context-sensitivity would be superficial.

Daniel Greco draws upon this distinction, as he is interested in the idea that we can compare different forms of epistemic contextualism according to their depth:

3. The non-absolutist view is usually motivated by the claim that when combined with certain set-theoretic principles, allowing for unrestricted quantification will lead to Russell-style paradoxes. 
Roughly, the sort of context-dependence posited by the superficial contextualist is eliminable, while the sort of context-dependence posited by the deep contextualist is not. The deep contextualist is contextualist "all the way down", while the superficial contextualist thinks that, once you start digging, you eventually hit some context-independent bedrock. Without worrying too much about exactly how far "all the way down" is, we can compare versions of contextualism for "depth" depending on just how many of our epistemological notions they take to be context-sensitive.

(2017: 114)

The extent to which a view is a deep form of contextualism is dependent upon whether the phenomena that knowledge attributions are used to talk about require context-sensitive language in order to be spoken of. For example, one thing that knowledge attributions are used to talk about are our beliefs. If it turns out that the phenomenon of having beliefs and having evidence for those beliefs is such that it is best captured using context-sensitive language, then I take it that this is a deeper form of contextualism. The same would hold if the form of justification required for knowledge itself required context-sensitive language in order to be described. But if the underlying phenomenon is itself relatively stable across contexts, then this looks like a more superficial form of contextualism. So what would the respective views actually look like? We'll begin by considering superficial forms of contextualism before considering certain deeper forms.

\section{Superficial Epistemic Contextualism}

One relatively superficial form of epistemic contextualism will state that the difference between knowledge that $p$ and a mere true belief that $p$ lies in whether the subject meets a minimum threshold of justification. ${ }^{4}$ We can view justification as lying along a single dimension, upon which the threshold sits. What makes this view contextualist is that the justificatory threshold for knowledge can shift across contexts, or put in a more precise metalinguistic form, the justificatory threshold required for a true knowledge attribution can shift across different contexts of utterance. Now on this view, it seems that the underlying phenomenon that knowledge attributions describe - that is, the level of justification held by a subject regarding a certain belief - is in fact an invariant phenomenon. The context-sensitivity only arises at the point of determining the truth conditions for knowledge attributions.

While I have employed the terminology of justification, we can outline superficial contextualist views using other frameworks as well. For example, imag-

4. Schaffer (2005) discusses this kind of view and attributes it to Cohen (1988).

Ergo •vol. 6, no. 24 2019 
ine a view that states that the difference between knowledge and true belief lies in the extent to which the subject can truth-track their belief in a set of nearby possible worlds (Nozick 1981). On this view, we can essentially place all possible worlds on a 1-dimensional scale in terms of their distance from the actual world. A context-sensitive threshold will then sit somewhere along that scale and will determine the set of possible worlds that the subject's belief must truth-track in (DeRose 1995). This will mean that in some contexts, the subject will have to truth-track her belief in more possible worlds, in others, fewer possible worlds. This will still be a superficial contextualist view because the underlying phenomenon of truth-tracking one's belief is itself invariant.

\section{Deep Epistemic Contextualism}

A deeper form of contextualism is one in which the underlying phenomenon is such that it requires an appeal to context in order to be understood. Many relevant alternatives views take this form. Let's say $S$ knows $\mathrm{p}$ in c only if $S$ can rule out all the alternatives that are relevant in c. Now, importantly, suppose there is no particular ordering to the alternatives, so that the fact that one alternative is relevant tells you nothing about whether other alternatives are relevant. On this account, there is nothing like an invariant scale of justification. Instead, the quality of the epistemic position will be dependent upon the alternatives that are relevant, and this too is a context-sensitive matter. It is in this sense that this is a deeper form of contextualism.

Just as with superficial contextualism, we can outline a deeper form of contextualism using the truth-tracking framework. Again, imagine a view where $S$ knows $p$ only if $S$ can truth-track her belief in all nearby possible worlds. But now, imagine that the similarity metric that determines the distance from possible worlds to the actual world is a context-sensitive matter. ${ }^{5}$ So in some contexts, the distance between $\mathrm{w}_{1}$ and the actual world will be less than the distance between $\mathrm{w}_{2}$ and the actual world, while in other contexts the reverse will be the case. Now we could still allow that there is a context-sensitive threshold between nearby and non-nearby possible worlds such that even once you fix the similarity metric, there is still a more superficial form of context-sensitivity. But the important point here is that because this view does not have a fixed notion of truth-tracking one's belief across possible worlds, the underlying phenomenon itself is contextsensitive. It is in this sense that this view would constitute a deeper form of epistemic contextualism. ${ }^{6}$

5. Heller (1999) explicitly defends a position of this kind.

6 . There are ways in which you could view the relevant alternatives framework and the truthtracking framework as equivalent, as (Heller 1999: 116) has noted. For any alternative q, if a subject is able to rule out $\mathrm{q}$, then we could say that the subject's belief is truth-tracked in all q worlds. The 
In this section, I have outlined the distinction I have in mind between deep and superficial contextualism. In the following section, I will analyse the way in which each type of view is able to capture the idea that knowledge is more valuable than true belief. Before I do so, however, it is worth approaching an issue that naturally arises when considering how contextualism impacts upon other epistemological debates. It might be thought that there is simply no straightforward link between epistemic contextualism as a linguistic theory about the truth of knowledge attributions and between epistemological theories that are concerned with knowledge (DeRose 2009: 18; Kornblith 2000). For the purposes of this paper, I will assume as the default position that the relation (or set of relations) that knowledge-attributing sentences describe is the same relation (or set of relations) that epistemologists are interested in when providing theories of knowledge. In doing so, I assume a close link between whether it is true to say "S knows $\mathrm{p}$ " within a context $\mathrm{c}$ and whether $\mathrm{S}$ does know $\mathrm{p}$ in $\mathrm{c}$. I consider this to be the default position for anyone-contextualist and otherwise-simply because it would be incumbent upon those who rejected this position to describe some other plausible way that there could be a link between the two fields of inquiry, without letting the "semantics float free of metaphysics", as McKenna (2015:501) has put it.7 In particular, if the default view is not held, then we face a potential dilemma. On the one hand, we run the risk of our philosophical account of knowledge being about something other than our ordinary conception insofar as it is divorced from our linguistic behaviour regarding knowledge terms. On the other hand, we run the risk that the truth values we assign to knowledge at-

converse could also be true as well: for any given set of worlds, if a subject's belief truth-tracks in those worlds, then we could say that there is an alternative consisting of those worlds that the subject is able to rule out. We cannot distinguish between the two views merely by appealing to truthtracking rather than ruling out alternatives. It might be thought that the similarity metric appealed to by the truth-tracking view constitutes an important difference between the two views. After all, this places an order on possible worlds that is lacking in the case of relevant alternatives. So if $\mathrm{w}_{1}$ is a closer possible world than $\mathrm{w}_{2}$, and $\mathrm{w}_{2}$ falls within the sphere of nearby worlds, then it follows that $\mathrm{w}_{1}$ does as well. The relevant alternatives framework does not allow for any similar kind of inference: the fact that alternative $q$ is relevant tells you nothing about whether any other alternatives are relevant. However, this difference really amounts to how much ordering is provided by the similarity metric. Imagine a relevant alternatives view that states that $\mathrm{q}_{1}$ and $\mathrm{q}_{2}$ are relevant. You could effectively get the same results with the truth-tracking view by providing a very partial ordering on possible worlds such that $\mathrm{q}_{1}$ and $\mathrm{q}_{2}$ worlds are the joint closest worlds to the actual world, and all other worlds are equally far behind, and so $\mathrm{q}_{1}$ and $\mathrm{q}_{2}$ worlds are the only worlds that count as nearby. Now this is probably not the kind of ordering that advocates of truth-tracking views usually have in mind, but it does show that in order to properly distinguish between these views, a fuller account of the similarity metric would be required.

7. We have seen that Sosa (2000) provides an alternative kind of view, in suggesting that philosophical (specifically, epistemological) theorising is contained within a single conversational context. But we have also seen that this is simply an implausible picture of how epistemological theorising proceeds. 
tributions are not values of truth in the proper sense insofar as they fail to track when knowledge is present.

Once the default view is accepted, then we see that the deep/superficial distinction has real philosophical importance. According to more superficial forms of contextualism, it is only knowledge attributions that display contextsensitivity, whereas other important epistemic notions (such as justification or truth-tracking) are invariant. But according to deeper forms of contextualism, those underlying notions may also be context-sensitive. In the following section, I will argue that this distinction impacts on the notion of epistemic value.

\section{Contextualism and the Value of Knowledge}

We saw earlier that Socrates's reasoning relies on the intuition of KVB:

KVB: Knowledge is more valuable than merely true belief.

Rather than investigating the plausibility of Socrates's reasoning on the basis of this intuition, I now want to cash out KVB in the following way:

Invariant Value: If $A$ knows $p$ and $B$ merely truly believes that $p$, then $A^{\prime}$ s epistemic position regarding $p$ is more valuable than $B^{\prime} s$ epistemic position regarding $\mathrm{p}$.

In what follows, I will argue that the manner in which Invariant Value is accounted for by the contextualist is dependent upon the depth of their contextualism. Let's begin by first considering a deeper form of contextualism-relevant alternatives contextualism:

Relevant alternatives: "S knows $\mathrm{p}$ " is true in c only if $\mathrm{S}$ can rule out the set of alternatives relevant in c.

As stated earlier, this is a deeper form of contextualism because the set of relevant alternatives is itself a context-sensitive matter. This view faces a problem in capturing Invariant Value, which can be illustrated with the following case. Imagine Jack and Jill are bird-watchers both watching the same bird, albeit separately from one another. They both believe that the bird is a goldcrest. Jack is able to rule out that the bird is a goldfinch, but not that it is a firecrest. Jill is able to rule out that it is a firecrest, but not that it is a goldfinch. Let's suppose that, the business of ruling out alternatives aside, they both meet all other conditions associated with knowledge (i.e., they believe, their beliefs are true, etc.). 
Meanwhile, in $c_{1}$-a nearby goldfinch conference - the set of relevant alternatives contains only the possibility that the bird is a goldfinch. In that context, Jack knows that the bird is a goldcrest (or it is true to say "Jack knows that the bird is a goldcrest" in $\mathrm{c}_{1}$ ). Jill, on the other hand, merely believes that the bird is a goldcrest in $c_{1}$. In $c_{2}-$ a nearby firecrest conference-the set of relevant alternatives contains only the possibility that the bird is a firecrest. As such, Jack merely truly believes that the bird is a goldcrest, while Jill knows that the bird is a goldcrest.

Let's label as ' $\mathrm{p}_{\mathrm{g}}$ ' the proposition that the bird is a goldcrest. From $\mathrm{c}_{1}$, plus Invariant Value, we can infer that Jack's epistemic position regarding $\mathrm{p}_{\mathrm{g}}$ is more valuable than Jill's epistemic position regarding $\mathrm{p}_{\mathrm{g}}$. From $\mathrm{c}_{2}$, plus Invariant Value, we can infer that Jill's epistemic position regarding $p_{g}$ is more valuable than Jack's epistemic position regarding $\mathrm{p}_{\mathrm{g}}$. So we reach:

Jack's epistemic position regarding $p_{g}$ is more valuable than Jill's epistemic position regarding $p_{g}$ and Jill's epistemic position regarding $p_{g}$ is more valuable than Jack's epistemic position regarding $\mathrm{p}_{\mathrm{g}}{ }^{8}$

This conjunction strikes the ear as contradictory, and this is confirmed if we accept something like the following principle:

Ordinal Value: For all $x, y$, and $p$, if $x^{\prime} s$ belief that $p$ is more valuable than $y^{\prime}$ s belief that $p$, then $y^{\prime} s$ belief that $p$ is not more valuable than $x^{\prime} s$ belief that $p$.

So Invariant Value, Relevant Alternatives, and Ordinal Value give rise to a contradictory situation. A natural way for the relevant alternatives theorist to fix this is to contextualise epistemic value in a manner that corresponds to the contextualisation of truth values of knowledge attributions. No longer does A's belief that $\mathrm{p}$ hold some value simpliciter; instead, the value of an epistemic position will always be relative to a context. We can capture this thought by replacing Invariant Value with Contextualised Value:9

Contextualised Value: If in c, A knows that $\mathrm{p}$ and B merely truly believes that $p$, then in $c, A^{\prime}$ s belief that $p$ is more valuable than B's belief that $p$.

8. In what follows I refer to this kind of case-where one agent knows $p$ in $c_{1}$ but not $c_{2}$ while another knows $\mathrm{p}$ in $\mathrm{c}_{2}$ but not $\mathrm{c}_{1}$ - as Jack and Jill cases.

9. We will also have to adjust Ordered Value so that it is relativized to a context in the following way: For all $\mathrm{x}, \mathrm{y}, \mathrm{p}$, and $\mathrm{c}$, if in $\mathrm{c} \mathrm{x}^{\prime} \mathrm{s}$ epistemic position regarding $\mathrm{p}$ is more valuable than $\mathrm{y}^{\prime} \mathrm{s}$ epistemic position regarding $\mathrm{p}$, then in $\mathrm{c} \mathrm{y}^{\prime} \mathrm{s}$ epistemic position regarding $\mathrm{p}$ is not more valuable than $x^{\prime}$ s epistemic position regarding $\mathrm{p}$. 
This would block the problematic inference drawn earlier. The idea outlined here is that it only makes sense to talk of the value of an epistemic position relative to a particular context, and within any particular context, knowing will be more valuable than merely believing. A key strength of this approach is that it manages to preserve KVB if we interpret KVB as restricted to within a context. This may well be a plausible route for the relevant alternatives theorist to take, and it is one I will return to in the next section, but for now I only want to note that the relevant alternatives view is forced into contextualising value in this way. In the remainder of this section, I will argue that the same cannot be said for more superficial forms of contextualism.

Consider the simplest form of superficial contextualism, according to which there is a 1-dimensional scale of justification along which a given belief will sit, and there is a context-sensitive threshold that a given belief must exceed in order for that belief to count as knowledge. How could this view accommodate the idea that knowledge is more valuable than true belief? The simplest way to do this would be to claim that the higher up on the invariant scale of justification a given belief sits, the more valuable it is. So if two believers A and B only differ with regard to their justification, and A knows while B merely truly believes, then A's belief is no more valuable than B's regardless of the context. This would be a way of making good of the claim that knowledge is more valuable than true belief. So this superficial form of contextualism can still provide an invariant notion of epistemic value, by aligning the scale of epistemic value with the invariant scale of justification.

Here is another way of looking at it: having a single invariant scale of justification essentially blocks Jack and Jill cases where Jack knows $\mathrm{p}$ while Jill doesn't in $c_{1}$, whereas Jill knows $p$ while Jack doesn't in $c_{2}{ }^{10}$ This is because if A holds a greater level of justification than B such that in c, A knows and B merely believes, A will hold the greater level of justification across all contexts. Justification is an

10. What about a superficial form of contextualism that depends on an $n$-dimensional scale where $n>1$ ? For example, you might think that the relevant difference between knowledge and true belief is a matter of evidence, where evidence can vary in both quantity and quality, and where the quantity and quality of one's evidence is an invariant matter. The threshold between knowledge and true belief can then be represented as a line through 2-dimensional space. The context-sensitivity would arise from the fact that the threshold can vary across contexts. Whether such a view can capture Jack and Jill cases is something of a complex matter that is beyond the scope of this paper. My speculation is this: if the knowledge threshold can only translate across contexts such that all possible thresholds of knowledge would be parallel with one another, then Jack and Jill cases cannot be captured. On the other hand, if the knowledge threshold can be rotated or distorted across contexts, then it will be possible to capture Jack and Jill cases. However, allowing for rotation or distortion across contexts is to allow that, while the two underlying dimensions of quality and quantity are invariant, the relative contribution they make towards the truth of knowledge attributions is context-sensitive, and so this would then constitute a deeper form of contextualism. 
invariant matter on this picture, and so the simplest way to capture the idea that knowledge is more valuable than true belief is simply to say that value tracks justification. This is not to say that the option of contextualising epistemic value is not available to superficial contextualism, just that the deep contextualist must contextualise epistemic value whereas the superficial contextualist can appeal to an invariant notion of epistemic value.

\section{Rejecting the Invariant Notion of Epistemic Value}

To summarise thus far, superficial and deep contextualism differ in how they are able to account for the distinctive value of knowledge. Superficial contextualism has two broad options available. First the superficial contextualist could claim that knowledge is always more valuable than a mere true belief because it will always sit higher on the invariant scale of justification. Alternatively, they could accept something like Contextualised Value and allow that the notion of epistemic value is itself a context-sensitive notion. The deep contextualist, on the other hand, has no invariant scale of justification that they can appeal to and so is forced to contextualise epistemic value. This in itself is an interesting result, partly because it shows the importance of the deep/superficial distinction, but also because it opens up certain argumentative possibilities. For instance, if one had good reason to think that epistemic value cannot be a context-sensitive notion, then this is a basis to argue against any deep form of contextualism. Furthermore, we have seen that superficial contextualism cannot allow for Jack and Jill cases, and so if such cases are possible, then this provides us with reason to reject superficial contextualism, and thus to contextualise epistemic value. For my own part, I will not pursue either of these options. I will argue, instead, that the option available to the superficial contextualist of keeping an invariant notion of epistemic value should be rejected and so contextualists - superficial and deep-should contextualise epistemic value.

At the beginning of this paper, we encountered the move from knowledge being more valuable than true belief (KVB) to the claim that there is some distinctive kind of value associated specifically with knowledge (VK). Furthermore, we saw that VK is itself a plausible principle insofar as it captures the fact that knowledge simply does play such a central role in our epistemic lives (i.e., it potentially provides a basis for action and assertion), and also has been of such primary focus in epistemological theorising.

The core claim of this section is that the superficial contextualist strategy of claiming that a belief is valuable to the extent that it is justified is one that will not be able to explain what is distinctively valuable about knowledge. Recall that, on this account, the threshold that a given subject needs to exceed in order for their 
true belief to constitute knowledge will vary along an invariant scale of justification across different contexts of utterance. Invariant Value (and thus, KVB) can be preserved because if $\mathrm{A}$ knows that $\mathrm{p}$ but $\mathrm{B}$ merely believes, $\mathrm{A}$ must sit higher on the scale of justification and thus have a more valuable epistemic position than B does. The problem with this view is that it doesn't explain why we would take knowledge to be of such central importance in our epistemic lives, rather than some epistemic state the threshold for which sits higher on the scale of justification. Assigning numeric values to the scale of justification, we can put the point as follows. If the knowledge threshold for a given context sits at 0.7 , then anyone that does know in that context is in a valuable epistemic position insofar as its justification value is some figure greater than 0.7. But then why, in this context, should we care about states that exceed a justification score of 0.7 , rather than 0.8 , 0.9 , etc.? ${ }^{11}$ If an epistemic position is just valuable to the extent that it is justified, it seems difficult to say why we should prioritise knowledge-with its threshold nearly always sitting somewhere between $o$ and $I$ on the justification scalerather some epistemic position that requires some greater level of justification.

Laurence BonJour (2010) draws upon similar considerations in order to reach a very different conclusion: infallibilism. He considers the possibility that the level of justification necessary for knowledge could sit on some point less than 1 on a wider scale. He argues that such a view would be unable to capture the fact that knowledge is a valuable kind of epistemic position that holds a kind of privileged position over other epistemic states. Say the given threshold sat at 0.8 ; BonJour argues that it then becomes mysterious why true beliefs that sit at 0.8 would hold a significant kind of value beliefs that sit at 0.799 lack, and indeed why we shouldn't subsequently prioritise epistemic states that sit even higher. Given the distinctive value of knowledge, the claim that the justification threshold could sit at any particular point less than 1 appears arbitrary. Thus, he argues that the only point at which the justification threshold could sit in order to make sense of the idea that knowledge holds a distinctive kind of epistemic value is 1 .

Of course, nearly all forms of contextualism are forms of fallibilism, and so no contextualist would accept BonJour's argument. But whereas BonJour argues that these considerations should lead us to accept infallibilism, I am arguing that we should reject something that BonJour's argument assumes and that is inherent in the contextualist view considered: that the value of knowledge can be accounted for via some underlying invariant scale. If we are to say that there is a distinctive kind of value associated with knowledge, this cannot be accounted

11. Pritchard (2010) discusses this issue in outlining the tertiary value problem of knowledge as the need to explain why the difference in value between knowledge and whatever falls short of it is one of kind and not merely degree. 
for by claiming that knowledge possesses some valuable property to some nonmaximal degree, because this then suggests that what we were really interested in all along is possessing that valuable property to the highest degree possible.

So although I have argued in this paper that the superficial contextualist is not forced to contextualise epistemic value in the same way that the deep contextualist is, I have subsequently argued in this section that the option available to the superficial contextualist of maintaining an invariant notion of epistemic value will not be satisfactory. Ultimately, then, epistemic contextualism ought to be committed to a contextualised notion of epistemic value.

Contextualists will typically characterise their view as merely a claim about knowledge attributions, and in doing so they give the impression that the commitments of their view are fairly light-particularly if one holds the prior view that natural languages have many such context-sensitive expressions-and that such commitments are limited to the linguistic domain. In this paper, I have sought to show that this is not the case: the contextualist is in fact committed to much more than insofar as they are committed to a particular account of epistemic value. To be clear, some contextualists have previously endorsed some form of contextualised epistemic value. Arguably, Heller does when he states that in attributing knowledge, "we are saying that someone who is in that epistemic condition has the property we care about in that context" (1999: 118). Similarly, a contextualised form of virtue epistemology will claim that exercising one's epistemic virtues is a source of epistemic value, and whether an agent has exercised their epistemic virtues in forming a true belief (and thus whether one has knowledge) is a context-sensitive matter (J. Greco 2004). In doing so, they will have a contextualised notion of epistemic value. However, this paper has argued that all contextualists are forced to contextualise epistemic value. Once we appreciate this insight, we start to see how the epistemic contextualism debate will impact upon other areas of epistemology, particularly upon other epistemic notions of which epistemic value is just one. If this paper is indicative of future findings, it may well be that the contextualist is committed to far more than has been previously thought.

\section{Acknowledgments}

Thanks to Nat Hansen, two anonymous referees, and the audience of a Work in Progress session at the University of Reading for their input on this paper. Their comments proved to be of great epistemic value in the context I found myself in! 


\section{References}

BonJour, Laurence (2010). The Myth of Knowledge. Philosophical Perspectives, 24(1), 57-83. https://doi.org/10.1111/j.1520-8583.2010.00185.x

Cohen, Stewart (1988). How to Be a Fallibilist. Philosophical Perspectives, 2, 91-123. https:// doi.org/10.2307/2214070

DePaul, Michael R. (2009). Ugly Analyses and Value. In Adrian Haddock, Alan Millar and Duncan Pritchard (Eds.), Epistemic Value (112-138). Oxford University Press. https://doi.org/10.1093/acprof:oso/9780199231188.003.0006

DeRose, Keith (1992). Contextualism and Knowledge Attributions. Philosophy and Phenomenological Research, 52(4), 913-929. https://doi.org/10.2307/2107917

DeRose, Keith (1995). Solving the Skeptical Problem. Philosophical Review, 104(1), 1-52. https://doi.org/10.2307/2186011

DeRose, Keith (2009). The Case for Contextualism. Oxford University Press. https://doi. org/10.1093/acprof:oso/9780199564460.001.0001

Greco, Daniel (2017). Cognitive Mobile Homes. Mind, 126(501), 93-121.

Greco, John (2004). A Different Sort of Contextualism. Erkenntnis, 61(2), 383-400. https:// doi.org/10.1007/s10670-004-9280-8

Heller, Mark (1999). The Proper Role for Contextualism in an Anti-Luck Epistemology. Philosophical Perspectives, 13, 115-129. https://doi.org/10.1111/0029-4624.33.s13.5

Kornblith, Hilary (2000). The Contextualist Evasion of Epistemology. Philosophical Issues, 10, 24-32. https://doi.org/10.1111/j.1758-2237.2000.tb00004.x

Kvanvig, Jonathan L. (2004). The Value of Knowledge and the Pursuit of Understanding. Cambridge University Press. https://doi.org/10.1017/CBO9780511498909

McKenna, Robin (2015). Contextualism in Epistemology. Analysis, 75(3), 589-503. https:// doi.org/10.1093/analys/anv029

Nozick, Robert (1981). Philosophical Explanations. Harvard University Press.

Pritchard, Duncan (2010). The Value Problem for Knowledge. In Duncan Pritchard, Alan Millar and Adrian Haddock (Eds.), The Nature and Value of Knowledge (5-24). Oxford: Oxford University Press. https://doi.org/10.1093/acprof:oso/9780199586264.001.0001

Schaffer, Jonathan (2005). What Shifts?: Thresholds, Standards, or Alternatives? In Gerhad Preyer and Georg Peter (Eds.), Contextualism in Philosophy: Knowledge, Meaning, and Truth (115-130). Oxford University Press.

Sosa, Ernest (2000). Skepticism and Contextualism. Philosophical Issues, 10, 1-18. https:// doi.org/10.1111/j.1758-2237.2000.tb00002.x

Stalnaker, Robert (2008). Our Knowledge of the Internal World. Oxford University Press. https://doi.org/10.1093/acprof:oso/9780199545995.001.0001

Zagzebski, Linda (2004). The Search for the Source of Epistemic Good. Metaphilosophy, 34(1/2), 12-28. https://doi.org/10.1111/1467-9973.00257 